\title{
Phosphodiesterase and cyclic adenosine monophosphate- dependent inhibition of T-lymphocyte chemotaxis
}

\author{
R. Hidi*, S. Timmermans*, E. Liu*, C. Schudt*, G. Dent*, S.T. Holgate*, R. Djukanović*
}

\begin{abstract}
Phosphodiesterase and cyclic adenosine monophosphate-dependent inhibition of $T$ lymphocyte chemotaxis. R. Hidi, S. Timmermans, E. Liu, C. Schudt, G. Dent, S.T. Holgate, R. Djukanović. (C) ERS Journals Ltd 2000.

ABSTRACT: There is abundant evidence for T-lymphocyte recruitment into the airways in allergic inflammatory responses. This study has tested the hypothesis that T-cell chemotaxis induced by platelet-activating factor (PAF) and human recombinant interleukin-8 (hrIL-8) can be attenuated by inhibition of phosphodiesterase activity and raised intracellular $3^{\prime}, 5^{\prime}$-cyclic adenosine monophosphate (cAMP) levels.

This study used theophylline, a nonselective phosphodiesterase (PDE) inhibitor, and rolipram, a selective PDE4 inhibitor, to study the effect of PDE inhibition on T-cell chemotaxis. The $\beta_{2}$-adrenoceptor agonist, salbutamol, the adenylyl cyclase activator, forskolin, and the cAMP analogue, dibutyryl cAMP (db-cAMP), were used to demonstrate a role for raised cAMP levels. T-cells were obtained from 10 atopic asthmatics, and the phenotype of migrating cells was examined by flow cytometry.

Theophylline caused an inhibition of both PAF-and hrIL-8-induced chemotaxis (mean \pm SEM maximum inhibition at $1 \mathrm{mM}: 73 \pm 4 \%$ and $48 \pm 8 \%$ for hrIL-8 and PAF, respectively) that was not specific for the CD4+, CD8+, CD45RO+ or CD45RA+ T-cell subsets. T-cell chemotaxis was more sensitive to treatment with rolipram whose effect was already significant from $0.1 \mu \mathrm{M}$ on hrIL-8-induced chemotaxis. Both a low concentration of salbutamol $(0.1 \mathrm{mM})$ and forskolin $(10 \mu \mathrm{M})$ potentiated the inhibitory effect of a low concentration of theophylline $(25 \mu \mathrm{M})$ on responses to PAF but not to hrIL-8. Finally, T-cell chemotaxis was also inhibited by db-cAMP.

It is concluded that attenuation of T-cell chemotaxis to two chemoattractants of relevance to asthma pathogenesis can be achieved via phosphodiesterase inhibition and increased intracellular $3^{\prime}, 5^{\prime}$-cyclic monophosphate using drugs active on cyclic nucleotide phosphodiesterase. This action may explain the anti-inflammatory effects of theophylline and related drugs in asthma.
\end{abstract}

Eur Respir J 2000; 15: 342-349.

\begin{abstract}
*University Medicine, Southampton General Hospital, Southampton, UK. ${ }^{\#}$ Byk Gulden, Dept of Biochemistry, Konstanz, Germany.
\end{abstract}

\author{
Correspondence: R. Djukanović \\ University Medicine CD144 \\ Southampton General Hospital \\ Tremona Road \\ Southampton, SO16 6YD \\ UK \\ Fax: 442380701771 \\ Keywords: Chemotaxis \\ $3^{\prime}, 5^{\prime}$-cyclic adenosine monophosphate \\ cyclic nucleotide phosphodiesterase \\ rolipram \\ theophylline \\ T-lymphocytes
}

Received: January 111999

Accepted after revision September 91999

Financial support from Byk Gulden Pharma, Konstanz, Germany, is gratefully acknowledged.
T-lymphocytes play a central role in orchestrating the inflammatory responses in asthma [1]. Increased numbers of CD4+ T-cells can be seen in the airways even in mild to moderate asthma [2], with further increases in seasonal, pollen-induced asthma [3], following allergen challenge in the laboratory $[4,5]$, and in association with experimental rhinovirus infections [6]. The authors have recently demonstrated increased chemotactic activity for T-cells in induced sputum from atopic asthmatic subjects [7] and have been able to induce prominent T-cell chemotaxis ex vivo with supernatants of bronchial biopsies stimulated with specific allergen [8]. These observations point to the existence of mechanisms which regulate the influx of T-cells into inflamed tissues.

Accumulating evidence suggests that theophylline has anti-inflammatory properties which could account for some of its therapeutic benefit in the treatment of asthma. Theophylline attenuates the experimentally induced late phase bronchoconstriction to inhaled allergen [9], a response that is associated with an influx of T-cells producing Th-2-type cytokines [10]. While the attenuation of late phase bronchoconstriction may represent prolonged bronchodilation occurring with regular administration of sustained-release preparations of theophylline, this action was observed at mean steady-state serum theophylline concentration below the accepted bronchodilator range [11]. In addition, changes in T-cell trafficking are associated with long-term theophylline therapy $[9,12]$ and some of its effects in asthma may be due to inhibition of T-cell recruitment into the airways $[12,13]$, with additional possible effects being reduction of T-cell activation [14] and proliferation [15], leading to amelioration of chronic airways inflammation.

In this study it has been hypothesized that inhibition of cyclic nucleotide phosphodiesterase (PDE) activity and increase in $3^{\prime}, 5^{\prime}$-cyclic adenosine monophosphate (cAMP) levels are involved in reducing T-cell chemotactic responses, providing targets for asthma drugs. The study focused on chemotaxis induced by platelet-activating factor (PAF) and human recombinant interleukin (hrIL-8), a CXC chemokine, using a modified Boyden chamber technique. PAF is a mediator with a wide range of inflammatory effects including T-cell chemotaxis [16], T-cell proliferation and IL-2 production $[9,17]$. IL-8 is expressed to an 
elevated degree in epithelial cells [18] and eosinophils of asthmatic subjects, and increased levels can be detected in bronchoalveolar lavage fluid [19] and sputum cells [20] of these patients. This chemokine may also contribute to airways inflammation by regulating both eosinophil [21] and T-cell chemotaxis [22].

To test the role of phosphodiesterase (PDE) enzymes in this response, this study used theophylline, a nonselective PDE inhibitor, and rolipram, a PDE4-selective inhibitor. At least eight different families of PDE isoenzymes (PDE1-8) have so far been identified in a variety of tissues and inflammatory cells [23, 24]. Inhibition of PDE-catalysed conversion of cyclic nucleotides to their inactive nucleotide metabolites results in elevated cAMP and $3^{\prime}, 5^{\prime}$-cyclic guanosine monophosphate (cGMP) levels which increase cyclic nucleotide-dependent protein kinase activity, causing inhibition of inflammatory cell functions. Although some of the activity of theophylline may be due to adenosine receptor antagonism [25] and catecholamine release [26], at least part of the action of theophylline is due to inhibition of PDE. The authors have used a PDE4 inhibitor, rolipram, to determine the effect of selectively elevating cAMP without affecting cGMP [27]. Although T-cells have been demonstrated to contain the isoenzymes PDE3 and PDE7 as well as PDE4 [28, 29], PDE3 inhibitors do not cause measurable increases in intracellular cAMP levels [29] and no selective inhibitors of PDE7 have been described. Selective PDE4 inhibitors are under investigation as potential novel anti-asthma drugs [30]. To investigate more specifically the role of raised cAMP in inhibiting T-cell chemotaxis, the authors have used salbutamol, a selective $\beta_{2}$-adrenoceptor agonist, and forskolin, an adenylyl cyclase activator, both of which raise intracellular cAMP levels, and dibutyryl cAMP (db-cAMP), an analogue of cAMP.

\section{Materials and methods}

\section{Reagents}

Roswell Park Memorial Institute (RPMI) 1640 medium, heat-inactivated foetal calf serum (FCS), 4-(2-hydroxyethyl)-1- piperazine-ethanesulfonic acid (HEPES), L-glutamine, sodium pyruvate, penicillin, streptomycin, fungizone, and phosphate-buffered saline without calcium and magnesium (PBS) were purchased from Gibco BRL Life Technology (Uxbridge, Middlesex, UK). Bovine serum albumin (BSA), 1-O-alkyl-2-acetyl-sn-glyceryl-3-phosphorylcholine (PAF), $\mathrm{N}^{6}, 2^{\prime}$-O-dibutyryl adenosine $3^{\prime}, 5^{\prime}$-cyclic monophosphate (db-cAMP), forskolin and salbutamol were purchased from Sigma Chemical Company (Poole, Dorset, UK). Lymphoprep $^{\mathrm{TM}}$ (sodium diatrizoate/polysucrose; 1.077 $\mathrm{g} \cdot \mathrm{mL}^{-1}$ ) was obtained from Nycomed Pharma AS (Oslo, Norway). Rabbit anti-mouse immunoglobulins antiserum (purified immunoglobulin fraction) was from Dako (High Wycombe, Buckingamshire, UK). Antibodies for panning for T-cell separation (anti-CD11b, anti-CD14, anti-CD16 and anti-CD19) and mouse anti-human monoclonal antibody $(\mathrm{mAb})$ against surface antigens (CD3, CD4, CD8, CD19, CD16, CD14, CD45RO and CD45RA) conjugated with fluorescein isothiocyanate (FITC) or phycoerythrin (PE) for flow cytometry were purchased from Serotec (Oxford, Oxfordshire, UK). hrIL8 was a gift from I. Lindley
(Sandoz, Vienna, Austria). Theophylline and rolipram were synthesized by Byk Gulden Pharma (Konstanz, Germany).

\section{Preparation of solutions}

Reagents were initially dissolved in appropriate solvents and dilutions made in RPMI 1640 containing 0.05\% (weight/volume) BSA. Anhydrous theophylline was dissolved in PBS at $10 \mathrm{mM}$ and used at $25 \mu \mathrm{M}, 100 \mu \mathrm{M}$, and 1 $\mathrm{mM}$. Salbutamol was initially dissolved in distilled water at $10 \mathrm{mM}$ and used at a final concentration of $0.1 \mathrm{nM}$. Forskolin was dissolved in ethanol at $10 \mathrm{mM}$ and used at $10 \mu \mathrm{M}$. Db-cAMP was dissolved in PBS at $10 \mathrm{mM}$ and used at 100 and $500 \mu \mathrm{M}$. Rolipram was prepared in $1 \%$ (volume/volume) dimethyl sulfoxide (DMSO) at $1 \mathrm{mM}$ and used at $0.1,1$ and $10 \mu \mathrm{M}$. PAF was dissolved in ethanol and diluted in RPMI 1640 + BSA to give concentrations of $0.1,1,10$ and $100 \mathrm{nM}$, with final ethanol concentrations being $<0.001 \%$. hrIL- 8 was prepared in PBS containing $0.1 \% \mathrm{BSA}$ at $100 \mu \mathrm{g} \cdot \mathrm{mL}^{-1}(12.5 \mu \mathrm{M})$ and used at 1.25 , 12.5 and $125 \mathrm{nM}$ and $1.25 \mu \mathrm{M}$.

\section{T-lymphocyte separation}

Ten asthmatics were recruited, none of whom were taking theophylline or inhaled corticosteroids for at least 2 yrs before blood donation. All were atopic, as defined by skin-prick tests to a panel of common aero-allergens (Dermatophagoides pteronyssinus, Dermatophagoides farinae, mixed grass pollens, mixed tree pollens, moulds, Aspergillus fumigatus, cat, dog and horse hair, mixed feathers). All of the subjects had normal lung function $(>85 \%$ of predicted) and used salbutamol on average less than once a day over a period of 2 weeks prior to drawing blood. They were thus classified as having mild persistent asthma.

T-cells were separated using a modification of the authors' previously described protocol [31]. Heparinized venous blood was diluted with an equal volume of PBS and layered onto Lymphoprep. Following centrifugation at $8,000 \times g$ for $25 \mathrm{~min}$ at $20^{\circ} \mathrm{C}$, mononuclear cells were aspirated, washed twice with PBS and resuspended in RPMI 1640 supplemented with $8 \mathrm{mM}$ HEPES, $2 \mathrm{mM}$ L-glutamine, $1 \mathrm{mM}$ sodium pyruvate, $100 \mu \mathrm{g} \cdot \mathrm{mL}^{-1}$ streptomycin, $100 \mathrm{U} \cdot \mathrm{mL}^{-1}$ penicillin, $0.5 \mathrm{mg} \cdot \mathrm{mL}^{-1}$ fungizone and $2 \%$ heat-inactivated FCS. Monocytes were removed by adherence to plastic for $1 \mathrm{~h}$. Lymphocytes were suspended in medium and allowed to recover overnight in a Petri dish at $37^{\circ} \mathrm{C}$ and $5 \% \mathrm{CO}_{2}$. In the authors' hands this significantly prevents cell from clumping, which otherwise makes it difficult to conduct chemotactic assays. T-cells were further purified from the remaining nonadherent cells by negative selection using panning with antiCD11b, anti-CD14, anti-CD16 and anti-CD19 antibodies as previously described [31]. Nonadherent cells were washed twice with PBS and resuspended at $5 \times 10^{6}$ cells $\cdot \mathrm{mL}^{-1}$ in RPMI 1640 supplemented with $8 \mathrm{mM}$ HEPES, $2 \mathrm{mM}$ L-glutamine, $1 \mathrm{mM}$ sodium pyruvate and $0.4 \%$ BSA. The purity of T-cells was $>96 \%$ as assessed by flow cytometry using anti-CD3 mAbs to identify T-cells and anti-CD19, anti-CD16 and anti-CD14 to detect any contaminating Blymphocytes, natural killer cells and monocytes, respectively. Viability, as assessed by trypan blue exclusion, was $>99 \%$. 


\section{T-cell chemotaxis}

Chemotaxis experiments were performed in 48-well microchemotaxis chambers (NeuroProbe Inc., Cabin John, MD, USA) using the same donors for both PAF and hrIL8. Concentration-response studies were first conducted to find the optimum concentration of chemoattractant for subsequent experiments using $0.1-100 \mathrm{nM}$ for PAF and $1.25 \mathrm{nM}-1.25 \mu \mathrm{M}$ for hrIL-8. Twenty-five microlitres of each chemoattractant diluted in RPMI 1640 containing $0.05 \%$ BSA was placed in the lower wells, which were separated from the upper wells by an $8-\mu \mathrm{m}$ pore-size polyvinyl-pyrridone (PVP)-free polycarbonate membrane (Osmonics Corp., Minnetonka, MN, USA). Fifty-microlitre aliquots of cell suspension containing $2.5 \times 10^{5}$ cells were placed in each upper well and the chamber incubated for $60 \mathrm{~min}$ at $37^{\circ} \mathrm{C}$ in $5 \% \mathrm{CO}_{2}$. The membrane was carefully removed and the upper side of the filter scraped to remove nonmigrated cells. The migrated cells on the lower side of the membrane were fixed with methanol, stained with May-Grünwald Giemsa, and the number of migrating T-cells counted in five high-power fields forming two perpendicular diameters of the areas corresponding to the wells.

\section{Drug treatment of T-cells}

To study the effect of theophylline and rolipram on chemotaxis induced by PAF and hrIL-8, optimum concentrations of chemoattractants obtained from concentrationresponse studies were used. The cells were preincubated either with the vehicle alone or with the drug under test prior to migration. Incubation times were $15 \mathrm{~min}$ for theophylline, rolipram and db-cAMP, and 30 min for forskolin and salbutamol.

In addition to the full range of concentrations, a suboptimal concentration of theophylline $\left(25 \mu \mathrm{M}, 4.5 \mu \mathrm{g} \cdot \mathrm{mL}^{-1}\right)$ was used in combination with either $0.1 \mathrm{nM}$ salbutamol or $10 \mu \mathrm{M}$ forskolin to study the presence of any synergy in inhibition of chemotaxis to hrIL-8 and PAF.

The extent of inhibition of chemotaxis was expressed as a percentage of control, determined from the number of migrating cells in the presence of the compound and the number of migrating cells in the presence of the chemoattractant alone (control). Control chemotactic responses are reported as chemotaxis index (the ratio of migration in the presence of stimulus to migration in the absence of stimulus).

\section{Flow cytometric analysis of migrating T-cell subsets}

Selectivity of theophylline inhibition of chemotaxis of T-cell subsets $\mathrm{CD} 4+$ and $\mathrm{CD} 8+$ and the resting/naïve $(\mathrm{CD} 45 \mathrm{RA}+)$ and activated/memory (CD45RO+) T-cells was studied by analysing the phenotype of migrated cells. In these experiments, cells were allowed to migrate through a PVP-coated membrane which prevents adherence of cells to the lower side of the membrane. Migrated cells were aspirated and incubated with fluorescent dye-labelled antibodies for $30 \mathrm{~min}$ at $4^{\circ} \mathrm{C}$. Dual-colour cytometry was performed using FITC/PE-conjugated antibodies: anti-CD3/ anti-CD4, anti-CD3/anti-CD8, anti-CD3/anti-CD45RA and
anti-CD3/anti-CD45RO. Using appropriate software in acquisition mode (FACScan Research; Becton Dickinson, San Jose, CA, USA), 10,000 cells were analysed using the Lysis II programme (Becton Dickinson) after gating for lymphocytes in forward and side scatter as previously described [32].

\section{Statistical analysis}

Comparisons between the extent of chemotaxis in the presence and absence of drugs in response to each stimulus were made by repeated-measures analysis of variance (ANOVA). For concentration-response studies, chemotaxis in the presence of drugs was compared with control by Dunnett's multiple comparisons test. Where two drugs were used in combination, post hoc comparisons between all groups were performed by the Tukey-Kramer test for multiple comparisons. In experiments with db-cAMP, where data diverged significantly from a normal distribution, analysis was performed by Friedman's nonparametric repeated-measures test followed by Dunn's multiple comparisons test. A p-value of $<0.05$ was accepted as significant.

\section{Results}

Concentration-response effects of human recombinant interleukin-8 and platelet-activating factor on T-cell chemotaxis

Both PAF and hrIL-8 resulted in a bell-shaped response that was maximal around $10 \mathrm{nM}$, inducing migration of $89 \pm 24$ and $21 \pm 2$ T-cells (mean \pm SEM) at $10 \mathrm{nM}$ PAF and $12.5 \mathrm{nM}$ IL-8, respectively (chemotaxis indices $6.4 \pm 1.2$ and $2.3 \pm 0.58$, respectively; fig. 1). The optimal concentrations, $10 \mathrm{nM}$ for PAF and $12.5 \mathrm{nM}$ for IL-8 were used in all subsequent experiments. Comparison of indices of chemotaxis showed $10 \mathrm{nM}$ PAF to be on average 3-fold more effective than hrIL-8 at $12.5 \mathrm{nM}$.

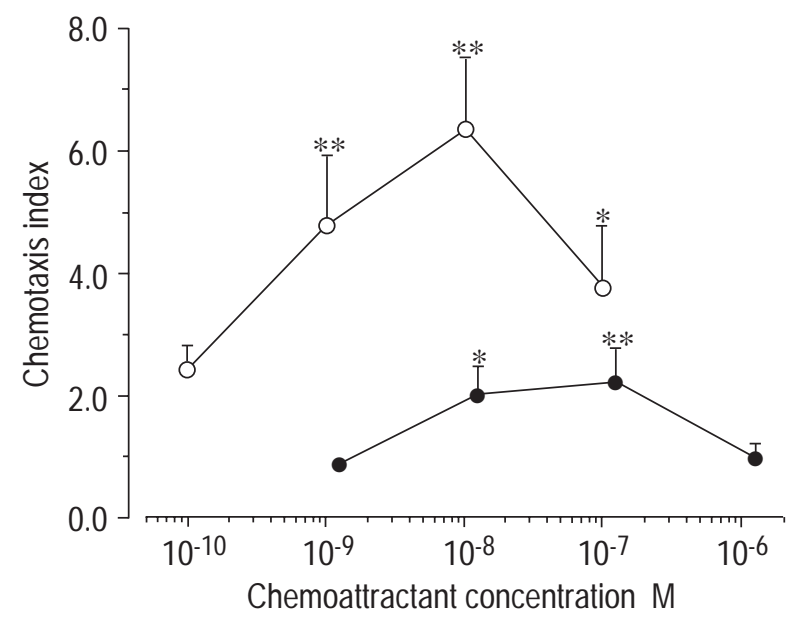

Fig. 1. - Concentration-response curves for peripheral blood T-cell chemotactic activity to platelet-activating factor $(O)$ and human recombinant interleukin-8 (O). T-cell migration was expressed as the chemotaxis index, derived from the number of migrating cells in the presence of the chemoattractant divided by the number of cells migrating in the presence of medium alone. Data are from 6 separate experiments (using cells from different donors) at all concentrations. The final results are expressed as mean \pm SEM. ${ }^{*}: \mathrm{p}<0.05 ; * *: \mathrm{p}:<0.01$. 


\section{Effect of theophylline on T-cell chemotaxis}

Theophylline exhibited no significant effect on spontaneous migration (medium alone, data not shown). A concentration-dependent inhibition by theophylline was noted of responses to both PAF and hrIL-8 (fig. 2), with the effect on hrIL-8 being significant at $100 \mu \mathrm{M}(36 \pm 8 \%$, $\mathrm{n}=10)$ and maximal at $1 \mathrm{mM}(73 \pm 4 \%, \mathrm{n}=6)$. However, the migration of T-cells to PAF was less sensitive to inhibition by theophylline, with significant effect seen only at $1 \mathrm{mM}(48 \pm 8 \% \mathrm{n}=6)$.

There was no preferential migration of either the CD4+ or CD8+ subsets of T-cells ( $\mathrm{n}=3$ ), nor of the CD45RO+ or CD45RA+ subsets $(n=6)$, either spontaneously or in response to PAF or hrIL-8 (table 1), as determined by the proportions of the subsets placed in the upper wells and those recovered from the lower wells. Theophylline did not have a selective inhibitory effect on the migration of any of the T-cell subsets studied (table 1).
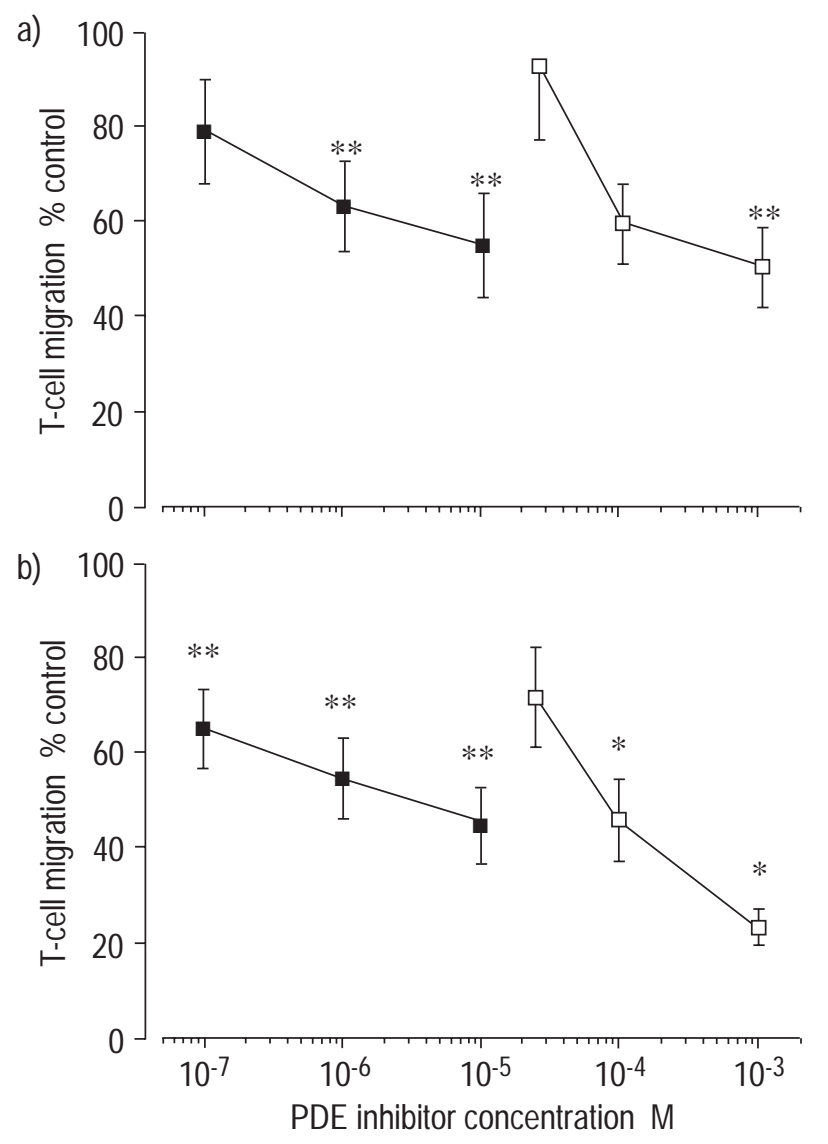

Fig. 2. - Effect of theophylline $(\square)$ and rolipram ( $\square$ ) on T-cell chemotaxis induced by $10 \mathrm{nM}$ platelet-activating factor (PAF) (a) and 12.5 $\mathrm{nM}$ human recombinant interleukin-8 (hrIL-8) (b). Data are from 10 separate experiments for $25 \mu \mathrm{M}$ theophylline, 6 separate experiments for the concentrations $100 \mu \mathrm{M}$ and $1 \mathrm{mM}$ of theophylline, and 7 separate experiments for rolipram at all concentrations. All experiments were performed in triplicate, using cells from different donors for each experiment, and are expressed as mean \pm SEM percentage of control (response to the chemoattractant in the absence of inhibitors). For theophylline experiments, control chemotactic indices were $6.6 \pm 3.3$ for PAF and $3.2 \pm 0.84$ for hrIL-8; for rolipram experiments, control chemotactic indices were $4.1 \pm 1.5$ for PAF and $3.3 \pm 0.56$ for hrIL-8. *: $\mathrm{p}<0.05 ; * *: \mathrm{p}<0.01$. PDE: phosphodiesterase.
Table 1. - Flow cytometric analysis of the migrating populations of T-lymphocytes to platelet-activating factor (PAF) and human recombinant interleukin-8: effects of theophylline

\begin{tabular}{llllllll}
\hline & \multicolumn{5}{c}{ Migrating cells \% of CD3+ cells } \\
\cline { 2 - 7 } & Control & \multicolumn{1}{c}{ Medium } & \multicolumn{2}{c}{ PAF } & \multicolumn{2}{c}{ IL-8 } \\
\cline { 2 - 7 } & & \multicolumn{7}{c}{-Theo + Theo } & - Theo & + Theo & -Theo & + Theo \\
\hline CD4+ & $72 \pm 2$ & $72 \pm 3$ & $72 \pm 2$ & $71 \pm 2$ & $72 \pm 2$ & $73 \pm 3$ & $71 \pm 3$ \\
CD8+ & $27 \pm 2$ & $28 \pm 2$ & $29 \pm 2$ & $28 \pm 2$ & $29 \pm 2$ & $30 \pm 3$ & $30 \pm 3$ \\
CD45RA+ & $53 \pm 9$ & $52 \pm 10$ & $47 \pm 10$ & $51 \pm 11$ & $50 \pm 9$ & $53 \pm 18$ & $52 \pm 15$ \\
CD45RO+ & $50 \pm 5$ & $51 \pm 4$ & $42 \pm 5$ & $47 \pm 6$ & $46 \pm 6$ & $47 \pm 8$ & $46 \pm 1$ \\
\hline
\end{tabular}

For each phenotypic marker, the results are expressed as mean \pm SEM percentages of CD3+ cells migrating through polyvinylpyrridone-coated membranes in response to the indicated stimuli. Data are from 3-6 experiments.

\section{Effect of rolipram on T-cell chemotaxis}

Rolipram had no effect on spontaneous migration (data not shown). A concentration-dependent inhibition by rolipram was obtained for responses to both hrIL-8 and PAF ( $\mathrm{n}=7$; fig. 2). The inhibition by rolipram was significant from $0.1 \mu \mathrm{M}$ for hrIL-8 $(35 \pm 8 \%)$ and from $1 \mu \mathrm{M}$ for PAF $(37 \pm 9 \%)$. The inhibitory effect of rolipram was smaller on migration to PAF as compared with hrIL-8 at all concentrations.

Effect of dibutyryl-3',5'-cyclic adenosine monophosphate on T-cell chemotaxis

Db-cAMP alone inhibited chemotaxis induced by both PAF and hrIL-8 in a concentration-dependent manner and to a comparable extent $(\mathrm{n}=7$, fig. 3 ).

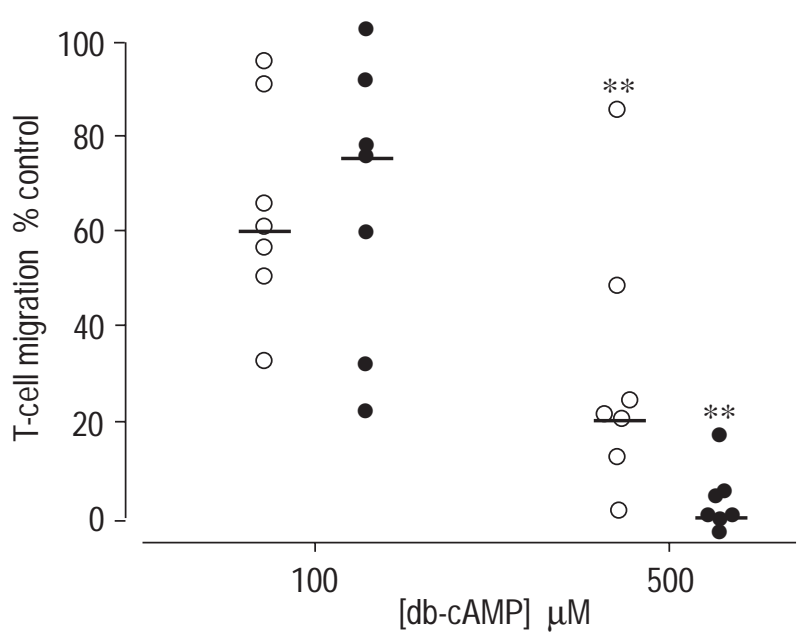

Fig. 3. - Effect of dibutyryl-3',5'-cyclic adenosine monophosphate (dbcAMP) on T-cell chemotaxis induced by platelet-activating factor (PAF; ○) and human recombinant interleukin-8 (hrIL-8; O). Data are from seven separate experiments, using cells from different donors, which were performed in triplicate and are expressed as a percentage of the control value (response to the chemoattractant in the absence of $\mathrm{db}$ cAMP). The median response indicated by the horizontal bar. The median control chemotactic indices were 3.8 (range 2.1-26) for PAF and 3.9 (range $1.1-19$ ) for hrIL-8. **: $\mathrm{p}<0.01$ versus $100 \mu \mathrm{m}$. 

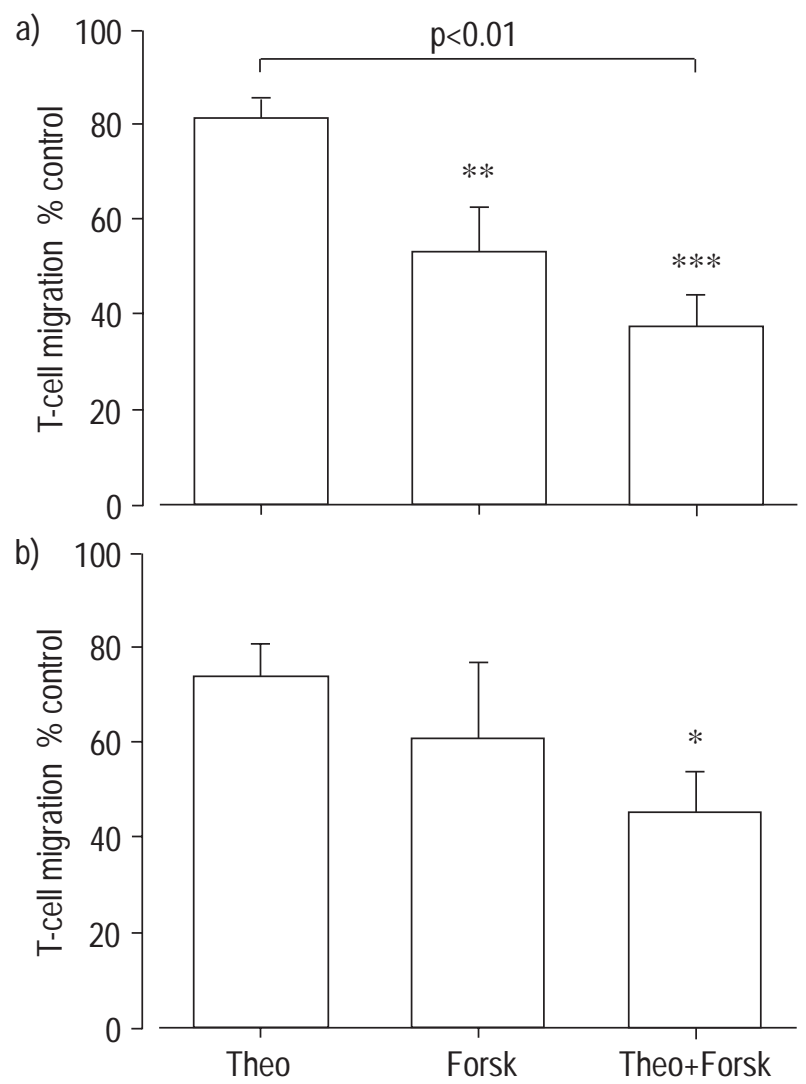

Fig. 4. - Effect of the combination of forskolin (Forsk) $(10 \mu \mathrm{M})$ and theophylline (Theo) $(25 \mu \mathrm{M})$ on T-cell chemotaxis induced by plateletactivating factor (PAF) (a) and human recombinant interleukin-8 (hrIL8) (b). Data are from six separate experiments, using cells from different donors and performed in triplicate and are expressed as mean \pm SEM percentage of control (response to the chemoattractant in the absence of any drugs). Control chemotactic indices were $6.2 \pm 1.6$ for PAF and $6.6 \pm 1.8$ for hrIL-8. *: $\mathrm{p}<0.05 ; * *: \mathrm{p}<0.01 ; * * *: \mathrm{p}<0.001$.

\section{Effect of the combination of theophylline and forskolin or salbutamol}

Forskolin $(10 \mathrm{mM})$ caused a significant inhibition of cell migration to $10 \mathrm{nM}$ PAF $(47 \pm 9 \%)$ but not to $12.5 \mathrm{nM}$ hrIL-8 ( $n=6$, fig. 4). When used at a low, sub-therapeutic concentration $(25 \mu \mathrm{M})$, theophylline did not inhibit chemotaxis to PAF or hrIL-8 (fig. 4). The actions of forskolin $(10 \mu \mathrm{M})$ and theophylline $(25 \mu \mathrm{M})$, when combined, significantly exceeded the inhibition by theophylline alone,

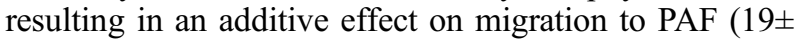
$4 \%$ inhibition by theophylline alone versus $63 \pm 6 \%$ inhibition by combined forskolin and theophylline, $\mathrm{p}<0.001$, $\mathrm{n}=6$; fig. 4). The same combination also had a greater effect on chemotaxis to hrIL- 8 than either compound alone $(27 \pm 8 \%$ inhibition by theophylline alone and $39 \pm$ $16 \%$ inhibition by forskolin and theophylline, $\mathrm{p}<0.05$, $\mathrm{n}=6$; fig. 4).

The effect of combined salbutamol and theophylline was also studied. Salbutamol alone at $0.1 \mathrm{nM}$ did not have a significant effect on migration to either PAF or hrIL-8 $(\mathrm{n}=8$; fig. 5). As with forskolin, the combination of salbutamol $(0.1 \mathrm{nM})$ and theophylline $(25 \mu \mathrm{M})$ significantly enhanced the effect of theophylline on the migration to PAF by a mean $285 \%$.
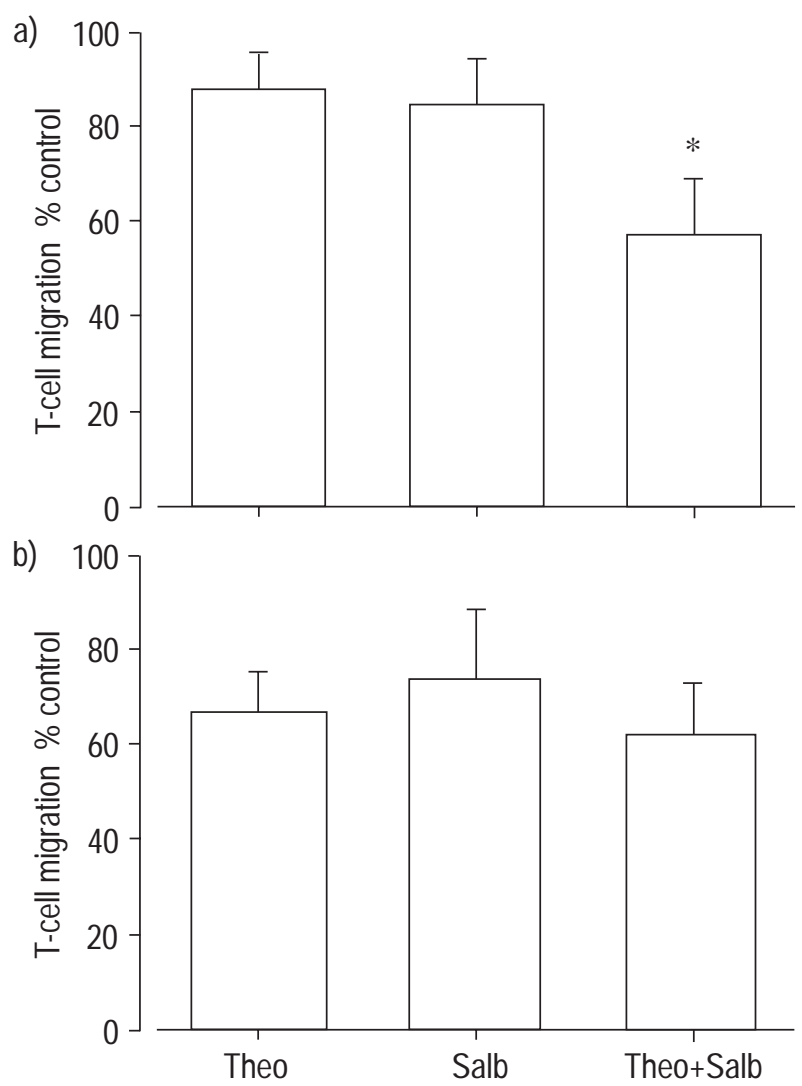

Fig. 5. - Effect of the combination of salbutamol (Salb) $(0.1 \mathrm{nM})$ and theophylline (Theo) $(25 \mu \mathrm{M})$ on T-cell chemotaxis induced by plateletactivating factor (PAF) (a) and human recombinant interleukin-8 (hrIL8) (b). Data are from eight separate experiments performed in triplicate using cells from different donors and are expressed as mean \pm SEM percentage of control (response to the chemoattractant in the absence of any drugs). Control chemotactic indices were $4.4 \pm 0.96$ for PAF and $6.6 \pm 1.8$ for hrIL-8. *: $\mathrm{p}<0.05$.

\section{Discussion}

Using an in vitro model of T-cell chemoattraction, it has been shown that inhibition of PDE activity and elevation of intracellular cAMP significantly reduces T-cell migration in response to two chemoattractants, PAF and hrIL-8, in a concentration-dependent manner. Both PAF and IL- 8 have been implicated in asthma pathogenesis and both are reported to act via G-proteins to activate a number of phospholipases and protein kinase C $[33,34]$, leading to activation of cell functions such as chemotaxis.

T-helper cells have been implicated in the pathology of asthma [1-5] and the presence of elevated levels of T-cell chemotactic activity in the epithelial lining fluid of asthmatic airways suggests a role for chemotaxis in alterations of T-cell trafficking through the lungs in asthma [7]. The withdrawal of theophylline from asthmatic patients has been demonstrated to lead to an increase in airway Tcell numbers, apparently reflecting a shift in the distribution of T-cells away from the circulation and into the airways [12]. This finding has led to the mode of action of theophylline in asthma being reappraised to include antiinflammatory as well as bronchodilator actions, and these anti-inflammatory actions may include suppression of Tcell chemotaxis. 
In this study, T-cells were used from atopic asthmatic donors because of possible differences in response to chemoattractants between atopic and nonatopic subjects. Furthermore, the in vivo effect of theophylline on T-cell accumulation in the lungs has been demonstrated in atopic asthmatics [9]. The current study indicates that both IL-8 and PAF induce chemotaxis of T-cells, resulting in bellshaped concentration-response curves, with maximum migration around $10 \mathrm{nM}$ for both mediators. The findings are not very different from previous reports that IL-8 has optimal activity on T-cells from $0.1-10 \mathrm{nM}$ [27], although the concentration of $125 \mathrm{nM}$ showed a slightly higher effect than $12.5 \mathrm{nM}$. Furthermore, the observations with PAF confirm the findings by McFADDEN et al. [16], showing the optimum concentration to be $10 \mathrm{nM}$.

Although both chemoattractants are known to utilize the same intracellular signalling pathways, the inhibition of hrIL-8-induced T-cell chemotaxis by theophylline was greater than that of PAF-induced responses. A possible explanation for this is the relatively higher potency of PAF as a chemoattractant for T-cells, possibly owing to cAMP depression by PAF via an activation of $\mathrm{G}_{\mathrm{i}}$ protein as shown in certain cells [35]. This may reduce the effect of drugs that inhibit cAMP breakdown.

The authors have not studied the effect of theophylline on PDE activity in this study. However, it has been demonstrated elsewhere that nonselective PDE inhibition by theophylline modulates the pro-inflammatory action of a number of cell types [36]. In a previous study, it was shown that human blood T-cells contain predominantly PDE3 and PDE4 activity, with significantly less PDE1, 2, 5 activity [28], while the presence of PDE7 has also been demonstrated [29]. This study does not provide insight into which of these isoforms was of relevance to T-cell chemotaxis inhibition by theophylline. However, the finding that the highly selective PDE4 inhibitor, rolipram, had a powerful inhibitory effect on the action of both chemoattractants used suggests that the PDE4 isoenzyme has an important modulatory role. Notably, maximum inhibition of hrIL-8-induced chemotaxis by theophylline $(1 \mathrm{mM})$ was higher than maximum inhibition by rolipram $(10 \mu \mathrm{M}): \sim 75 \%$ and $55 \%$ for theophylline and rolipram, respectively, which suggests an additional contribution of another PDE isoenzyme(s). Although PDE3 inhibition neither elevates intracellular cAMP levels nor suppresses IL-2 production in T-cells, the presence of a PDE3 inhibitor augments significantly both the cAMP elevation and the inhibition of IL-2 release induced by the PDE4 inhibitor, rolipram [29]. It is possible, therefore, that a nonselective PDE inhibitor, such as theophylline, can exert greater effects on T-cells than can be accomplished with a selective PDE4 inhibitor alone. PDE3 inhibitors were not included in the present study owing to their lack of a direct effect on T-cell cAMP levels and functions. As PDE4 inhibitors are under active consideration as potential novel anti-asthma drugs, the authors chose to concentrate on this class of compounds rather than inhibitors of other PDE isoenzyme families.

While some of the activity of theophylline can be attributed to adenosine receptor antagonism [37], it is less likely that this mechanism has been operative in the current study in view of observations that T-cells possess a high adenosine deaminase activity and do not produce adenosine [38]. Within the therapeutic range, theophyl- line increases intracellular levels of cAMP with an associated reduction in intracellular calcium, resulting in inhibition of calcium-dependent cell functions such as chemotaxis [39]. An increase in intracellular calcium concentrations following exposure to chemoattractants has been described in T-cell responses to IL-8, IL-1 $\alpha$, and IL$1 \beta[40]$.

Selectivity of chemoattractants for T-cell subsets is a recognized phenomenon. Thus, IL-16 is a chemoattractant selective for CD4+ T-cells [41] and regulated on activation, normal T-cell expressed and secreted (RANTES) for CD4+/CD45RO+ T-cells [42], although there is one report that RANTES can also induce chemotaxis of CD8+ T-cell clones [43]. To study the specificity of chemoattractants for different types of T-cell, one approach has been to separate the subsets before migration. However, the authors have chosen to use the entire CD3+ population since the effects of complex interactions between the two subsets on chemotaxis are not known. The authors have not shown any evidence of selectivity of either PAF or hrIL-8 on either the CD4+ or CD8+ subsets, which is in agreement with previous studies with IL-8 $[22,44]$. The inhibition of T-cell chemotaxis by theophylline did not reveal specificity for any of the subsets analysed. These findings are in keeping with the in vivo effects of theophylline demonstrated by KIDNEY et al. [12], who found that withdrawal of theophylline treatment from moderately severe asthmatics resulted in increased tissue and decreased blood CD4+ and CD8+ Tcells in a nonselective manner.

Human T-cells can also be divided into two distinct populations based on the expression of isoforms of the leukocyte common antigen (CD45), CD45RA+ and CD45RO+, differentiating between naïve/resting and memory/activated T-cells [45]. In contrast to a previous report [46], the authors have found no difference between the migratory responses of the CD45RA+ and CD45RO+ phenotypes to hrIL-8. It is possible that these differences are due to different methods or the fact that T-cells were used from the blood of atopic asthmatic donors. In this study, the cells migrated through a PVP-treated membrane to avoid adherence of the cells. This ensured that there was no interference with cell migration, especially for CD45RO+ cells which are thought to be more adherent than their CD45RA+ counterparts [44].

If the mechanism of action of theophylline is at least partly mediated via elevation of intracellular cAMP, then it is likely that this may be augmented by the addition of cAMP-inducing agents such as forskolin or a $\beta$-adrenoceptor agonist, such as salbutamol. When used alone at a low concentration of $0.1 \mathrm{nM}$, salbutamol did not show an inhibitory effect on the migration to either PAF or hrIL-8. However, when this concentration of salbutamol was used in conjunction with a low concentration of theophylline $(25 \mu \mathrm{M})$ an additive effect on PAF- but not hrIL-8-induced chemotaxis was observed, possibly owing to a lower degree of cAMP-dependent protein kinase activation following PAF ( $\mathrm{G}_{\mathrm{i}}$-inhibition) compared to IL-8. There was no indication of synergy between theophylline and salbutamol, however, which may be due to the low concentrations of salbutamol and theophylline used. As the degree both of adenylyl cyclase activation and of PDE inhibition is likely to be small, the uninhibited portion of PDE activity could quite rapidly hydrolyse the salbutamol-induced cAMP. 
Although the current study did not measure levels of intracellular cAMP, the fact that its analogue, db-cAMP, used at concentrations previously described as having an inhibitory effect on IL-2 production [47], was able to potently inhibit T-cell chemotaxis to both PAF and hrIL-8 suggests that cAMP is able to modulate T-cell chemotaxis. The role of cAMP was further studied by using forskolin, which bypasses cell surface receptors to activate adenylyl cyclase directly. T-cells were treated with $10 \mu \mathrm{M}$ forskolin, a concentration used in previous studies to demonstrate inhibition of rat T-cell chemotaxis to vasoactive intestinal peptide [48] and shown to potentiate the effect of PDE4 inhibitors on cytokine production [47]. Forskolin significantly inhibited the migration to PAF but not to hrIL-8 when used alone, but inhibited responses to both stimuli significantly when combined with theophylline. Based on mechanistic criteria, it is most likely that the use of theophylline and forskolin reduced responses to PAF via combined effects of PDE inhibition and activation of adenylyl cyclase on cAMP levels. As in the case of salbutamol, forskolin did not exhibit synergy with theophylline. Given that forskolin alone produced significant suppression of PAF-induced T-cell chemotaxis, PDE inhibition might be expected to potentiate this effect substantially by retarding enzymatic hydrolysis of the forskolin-evoked cAMP. It is possible that the degree of inhibition of PDE by $25 \mu \mathrm{M}$ theophylline is insufficient to exhibit synergy with forskolin, leading to a merely additive effect on chemotaxis.

In summary, the authors confirm previous investigations describing a chemotactic activity of platelet-activating factor and interleukin-8 for T-cells and show that both can be attenuated by phosphodiesterase inhibition and raising $3^{\prime}, 5^{\prime}$-cyclic adenosine monophosphate levels. It has been shown that theophylline is capable of inhibiting chemotaxis induced by these two chemoattractants. Importantly, theophylline is able to attenuate chemotaxis at low concentrations in combination with salbutamol, a drug combination that is often used in the treatment of asthma. It is concluded that $3^{\prime}, 5^{\prime}$-cyclic adenosine monophosphate elevating drugs used in the therapy of asthma inhibit Tlymphocyte chemotaxis, an action that may contribute to the suppression of chronic airways inflammation by theophylline and related drugs in asthma.

Acknowledgements. The authors thank W.H. Ng and $\mathrm{H}$. Tenor for their helpful discussions and comments on the manuscript, J. Shute for providing human recombinant interleukin- 8 and $\mathrm{H}$. Long for helping with patient recruitment.

\section{References}

1. Kay AB. Lymphocytes in asthma. Respir Med 1991; 85: 87-90.

2. Louis R, Shute J, Biagi S, et al. Cell infiltration, ICAM-1 expression, and eosinophil chemotactic activity in asthmatic sputum. Am J Respir Crit Care Med 1997; 155: 466-472.

3. Djukanović R, Feather I, Gratziou C, et al. Effect of natural allergen exposure during the grass pollen season on airways inflammatory cells and asthma symptoms. Thorax 1996; 51: 575-581.

4. Metzger WJ, Zavala D, Richerson HB. Local allergen challenge and bronchoalveolar lavage of allergic asthmatic lungs. Am Rev Respir Dis 1987; 135: 433-440.
5. Ohashi Y, Motojima S, Fukuda T, Makino S. Airway hyperresponsiveness, increased intracellular spaces of bronchial epithelium, and increased infiltration of eosinophils and lymphocytes in bronchial mucosa in asthma. Am J Respir Crit Care Med 1992; 145: 1469-1476.

6. Fraenkel DJ, Bardin PG, Sanderson G, Lampe F, Johnston SL, Holgate ST. Lower airways inflammation during rhinovirus colds in normal and in asthmatic subjects. $A m J$ Respir Crit Care Med 1995; 151: 879-886.

7. Hidi R, Louis R, Holgate S, Djukanović R. Chemotactic activity for T-cells detected in sputa from atopic asthmatics. Am J Respir Crit Care Med 1997; 155: A542.

8. Hidi R, Riches V, Holgate ST, Djukanović R. Chemotactic activity for T-cells generated in an explant of biopsies from atopic asthmatic patients. Am J Respir Crit Care Med 1997; 155: A816.

9. Ward AJM, McKenniff M, Evans JM, Page CP, Costello JF. Theophylline - an immunomodulatory role in asthma? Am Rev Respir Dis 1993; 147: 518-523.

10. Ying S, Durham SR, Corrigan CJ, Hamid Q, Kay AB. Phenotype of cells expressing mRNA for TH2-type (interleukin 4 and interleukin 5) and TH1-type (interleukin 2 and interferon $\gamma$ ) cytokines in bronchoalveolar lavage and bronchial biopsies from atopic asthmatic and normal control subjects. Am J Respir Cell Mol Biol 1995; 12: 477-487.

11. Mitenko PA, Ogilvie RI. Rational intravenous doses of theophylline. N Engl J Med 1973; 289: 600-603.

12. Kidney JC, Dominguez M, Taylor PM, Rose M, Chung $\mathrm{KF}$, Barnes PJ. Immunomodulation by theophylline in asthma: demonstration by withdrawal of therapy. $A m J$ Respir Crit Care Med 1995; 151: 1907-1914.

13. Djukanović R, Finnerty JP, Lee C, Wilson S, Madden J, Holgate ST. The effects of theophylline on mucosal inflammation in asthmatic airways: biopsy results. Eur Respir J 1995; 8: 831-833.

14. Scordamaglia A, Ciprandi G, Ruffoni S, et al. Theophylline and the immune response: in vitro and in vivo effects. Clin Immunol Immunopathol 1988; 48: 238-246.

15. Limatibul S, Shore A, Dosch HM, Gelfand EW. Theophylline modulation of E-rosette formation: an indicator of T-cell maturation. Clin Exp Immunol 1978; 33: 503513.

16. McFadden RG, Bishop MA, Caveney AN, Fraher LJ. Effect of platelet activating factor (PAF) on the migration of human lymphocytes. Thorax 1995; 50: 265-269.

17. Barrett ML, Lewis GP, Ward S, Westwick J. Plateletactivating factor modulates interleukin-2 proliferation of human T-lymphoblasts. Br J Pharmacol 1986; 89: $505 \mathrm{P}$.

18. Marini M, Vittori E, Hollemborg J, Mattoli S. Expression of the potent inflammatory cytokines, granulocytemacrophage-colony-stimulating factor and interleukin-6 and interleukin-8, in bronchial epithelial cells of patients with asthma. J Allergy Clin Immunol 1992; 89: 10011009.

19. Yousefi S, Hemmann S, Weber M, et al. IL-8 is expressed by human peripheral blood eosinophils: evidence for increased secretion in asthma. J Immunol 1995; 154: 54815490.

20. Konno S, Gonokami Y, Kurokawa M, et al. Cytokine concentrations in sputum of asthmatic patients. Int Arch Allergy Immunol 1996; 109: 73-78.

21. Shute JK, Lindley I, Peichl P, Holgate ST, Church MK, Djukanović R. Mucosal IgA is an important moderator of eosinophil responses to tissue-derived chemoattractants. Int Arch Allergy Immunol 1995; 107: 340-341. 
22. Larsen CG, Anderson AO, Appella E, Oppenheim JJ, Matsushima K. The neutrophil-activating protein (NAP1) is also chemotactic for T-lymphocytes. Science 1989; 243: 1464-1466.

23. Beavo JA, Reifsnyder DH. Primary sequence of cyclic nucleotide phosphodiesterase isozymes and the design of selective inhibitors. Trends Pharmacol Sci 1990; 11: 150155.

24. Soderling SH, Bayuga SJ, Beavo JA. Cloning and characterization of a cAMP-specific cyclic nucleotide phosphodiesterase. Proc Natl Acad Sci USA 1998; 95: 8991-8996.

25. Fredholm BB. Theophylline actions on adenosine receptors. Eur J Respir Dis Suppl. 1980; 109: 29-36.

26. Poisner AM. Direct stimulant effect of aminophylline on catecholamine release from the adrenal medulla. Biochem Pharmacol 1973; 22: 469-476.

27. Verghese MW, McConnell RT, Strickland AB, et al. Differential regulation of human monocyte-derived TNF alpha and IL-1 beta by type IV cAMP-phosphodiesterase (cAMP-PDE) inhibitors. J Pharmacol Exp Ther 1995; 272: 1313-1320.

28. Tenor H, Staniciu L, Schudt C, et al. Cyclic nucleotide phosphodiesterases from purified human CD4+ and CD8+ T-lymphocytes. Clin Exp Allergy 1995; 25: 616-624.

29. Giembycz MA, Corrigan CJ, Seybold J, Newton R, Barnes PJ. Identification of cyclic AMP phosphodiesterases 3, 4 and 7 in human CD4+ and CD8+ T-lymphocytes: role in regulating proliferation and the biosynthesis of interleukin-2. Br J Pharmacol 1996; 118: 1945-1958.

30. Torphy TJ. Phosphodiesterase isozymes: molecular targets for novel anti-asthma agents. Am J Respir Crit Care Med 1998; 157: 351-370.

31. Stanciu LA, Shute J, Holgate ST, Djukanović R. Production of IL-8 and IL-4 by positively and negatively selected CD4+ and CD8+ human T-cells following a four-step cell separation method including magnetic cell sorting (MACS). J Immunol Methods 1996; 189: 107-115.

32. Wilson JW, Djukanović R, Howarth PH, Holgate ST. Lymphocyte activation in bronchoalveolar lavage and peripheral blood in atopic asthma. Am Rev Respir Dis 1992; 145: 958-960.

33. Kravchenko W, Pan Z, Han J, Herbert JM, Ulevitch RJ, Ye RD. Platelet-activating factor induces NF- $\kappa B$ activation through a $\mathrm{G}$ protein-coupled pathway. J Biol Chem 1995; 270: 14928-14934.

34. Murphy PM. The molecular biology of leukocyte chemoattractant receptors. Annu Rev lmmunol 1994; 12: 593-633.

35. Williams KA, Haslam RJ. Effects of $\mathrm{NaCl}$ and GTP on the inhibition of platelet adenylate cyclase by 1-Ooctadecyl-2-O-acetyl-sn-glyceryl-3-phosphorylcholine (synthetic platelet-activating factor). Biochim Biophys Acta 1984; 770: 216-223.
36. Sinha B, Semmler J, Eisenhut T, Eigler A, Endres S. Enhanced tumor necrosis factor suppression and cyclic adenosine monophosphate accumulation by combination of phosphodiesterase inhibitors and prostanoids. Eur $J$ Immunol 1995; 25: 147-153.

37. Ukena D, Schudt C, Sybrecht GW. Adenosine receptorblocking xanthines as inhibitors of phosphodiesterase isozymes. Biochem Pharmacol 1993; 45: 847-851.

38. Barankiewicz J, Ronlov G, Jimenez R, Gruber HE. Selective adenosine release from human $\mathrm{B}$ but not $\mathrm{T}$ lymphoid cell line. J Biol Chem 1990; 265: 15738-15743.

39. Nielson CP, Crowley JJ, Morgan ME, Vestal RE. Polymorphonuclear leukocyte inhibition by therapeutic concentrations of theophylline is mediated by cyclic3',5'-adenosine monophosphate. Am Rev Respir Dis 1988; 137: 25-30.

40. Bacon KB, Westwick J, Camp RD. Potent and specific inhibition of IL-8-, IL-1 $\alpha$ - and IL-1 $\beta$ - induced in vitro human lymphocyte migration by calcium channel antagonists. Biochem Biophys Res Commun 1989; 165: 349-354.

41. Cruikshank WW, Center DM, Nisar N, et al. Molecular and functional analysis of a lymphocyte chemoattractant factor: association of biologic function with CD4 expression. Proc Natl Acad Sci USA 1994; 91: 5109-5113.

42. Schall TJ, Bacon K, Toy KJ, Goeddel DV. Selective attraction of monocytes and T-lymphocytes of the memory phenotype by cytokine RANTES. Nature 1990; 347 : 669-671.

43. Loetscher P, Seitz M, Clark-Lewis I, Baggiolini M, Moser B. Monocyte chemotactic proteins MCP-1, MCP-2, and MCP-3 are major attractants for human CD4+ and CD8+ T-lymphocytes. FASEB $J$ 1994; 8: 1055-1060.

44. Tanaka J, Nomiyama H, Yamamoto T, Hamada F, Kambara T. T-cell chemotactic activity of cytokine LD78: a comparative study with interleukin-8, a chemotactic factor for the T-cell CD45RA+ phenotype. Int Arch Allergy Immunol 1993; 100: 201-208.

45. Akbar AN, Terry L, Timms A, Beverley PC, Janossy G. Loss of CD45R and gain of UCHL1 reactivity is a feature of primed T-cells. J Immunol 1988; 140: 2171-2178.

46. Newman I, Wilkinson PC. Locomotor responses of human CD45 lymphocyte subsets: preferential locomotion of CD45RO+ lymphocytes in response to attractants and mitogens. Immunology 1993; 78: 92-98.

47. Lacour M, Arrighi JF, Muller KM, Carlberg C, Saurat JH, Hauser C. cAMP up-regulates IL-4 and IL-5 production from activated $\mathrm{CD} 4+\mathrm{T}$-cells while decreasing IL-2 release and NF-AT induction. Intern Immunol 1994; 6: 1333-1343.

48. Garrido E, Delgado M, Martinez C, Gomariz RP, De la Fuente M. Pituitary adenylate cyclase-activating polypeptide (PACAP38) modulates lymphocyte and macrophage functions: stimulation of adherence and opposite effect on mobility. Neuropeptides 1996; 30: 583-595. 